\title{
Awareness of attention allocation and time estimation accuracy
}

\author{
DAN ZAKAY and YEHOSHUA TSAL \\ Tel Aviv University, Tel Aviv, Israel
}

\begin{abstract}
Subjects performed a psychomotoric task and gave a prospective verbal estimate of its duration. One group of subjects was then made aware of optimal division of attention between the psychomotoric task and the passage of time, and again performed the task and prospectively estimated its duration. It was found that the accuracy of the time estimation markedly improved for that group of subjects relative to a control group whose awareness of the division of attention was not raised. Implications for understanding time estimation processes are discussed.
\end{abstract}

Time judgments of short intervals are generally found to be positively correlated with the objective clock time of the estimated intervals, but the correlations differ significantly from 1.0 (Hicks \& Miller, 1976). Giving feedback on the accuracy of time estimation was found to decrease the absolute estimation error of short intervals (e.g., Hicks, 1976; Hicks \& Miller, 1976). A different approach for reducing time estimation inaccuracy was attempted in the present study; it is based on an attentional model for prospective time estimation. Proponents of the attentional approach (e.g., Frankenhauser, 1959; Hicks, Miller, Gaes, \& Bierman, 1977; Priestly, 1968) view time estimation as a direct function of the amount of attention allocated for processing the passage of time. The more attention is allocated to a cognitive processor of time, the longer duration estimates will be. This model has been validated in many experiments in the frame of a prospective paradigm in which subjects knew in advance that they would be required to estimate time (e.g., Burnside, 1971; Cahoon \& Edmonds, 1980; Hicks et al., 1977; Lordahl \& Berkowitz, 1975; Vroon, 1970; Zakay \& Fallach, 1984; Zakay, Nitzan, \& Glicksohn, 1983).

The explanation suggested by the attentional model for inaccuracy in time judgments focuses on the suboptimal division of attention between the passage of time and the concurrent task performed during the target interval. It is suggested here that overestimation is a result of allocating a substantial amount of attentional resources to the passage of time, whereas underestimation results from allocating a small amount of available resources to the passage of time. It is commonly accepted that there is considerable diversity in the efficiency with which tasks may be time shared, resulting either from differences in basic time sharing ability or from differences in practice (Wickens, 1984). It also was found, however, that it is possible to train and improve time sharing skills regarding psychomotoric tasks (e.g., Gopher \& Brickner, 1980). On the basis of these findings, we hypothesized that by

Correspondence may be addressed to Dan Zakay, Department of Psychology, Tel Aviv University, Tel Aviv 69978, Israel. making estimators aware of the need for an optimal time sharing and division of attention in the context of a prospective time estimation, estimation accuracy would be improved.

\section{METHOD}

\section{Subjects}

Fifty undergraduate students at Tel Aviv University participated in the experiment in partial fulfillment of a course requirement.

\section{Experimental Tasks and Procedure}

The subjects were required to disassemble a three-dimensional puzzle and to reassemble it again. This was done within a prospective time estimation paradigm; namely, subjects were told that upon completing the task, they would be asked to give a verbal estimate in seconds of the duration it took them to perform the task. The subjects were tested individually. Upon entering the experimental room, they were told that they were going to participate in an experiment intended to test the psychomotoric and time estimation abilities of people. The subjects were asked to remove their wristwatches, and the nature of the task was explained. Then, the task was performed for the first time, and a verbal estimation was given by the subject. This session was not included in the analyses. Its purpose was to familiarize subjects with the task and to prevent a possible time order error later on (Fraisse, 1984). Then the task was repeated.

Following this session, each subject was assigned at random to either the experimental or the control group. The experimental group subjects heard a lecture in which the role of attention in a task such as the one they had performed was explained. It was explained that the more attention is devoted to processing the passage of time, the longer time estimates will be, and that in order to achieve accurate time estimates without harming the performance of the psychomotoric task, they should employ an optimal division of attention between the two; that is, the exact amount of attention needed for an accurate performance of each task should be allocated to it, no more and no less. Then the subjects trained themselves in utilizing an optimal division of attention by performing a different task involving a maze solution. Upon completing the training phase, the subjects were asked to perform the experimental task for the third time and to give a verbal estimate of its duration. Subjects in the control group went through all the procedures described above, except that instead of the explanation given to the experimental group, they heard a lecture about the different meanings of time in different societies, and performed the maze task without any reference to attention. The actual times it took each subject to complete the experimental task in the second and third sessions, and the verbal estimates given to those intervals were recorded. It should be emphasized that at no stage of the experiment were subjects given any feedback. 
Table 1

Means and Standard Deviations of Estimation Accuracy Scores

\begin{tabular}{lccccccc}
\hline & \multicolumn{3}{c}{ Experimental Group } & & \multicolumn{3}{c}{ Control Group } \\
\cline { 2 - 4 } \cline { 6 - 8 } & $M$ & $S D$ & $N$ & & $M$ & $S D$ & $N$ \\
\hline Before Training & 0.95 & 0.05 & 25 & & 0.98 & 0.08 & 25 \\
After Training & 1.01 & 0.05 & 25 & & 0.97 & 0.07 & 25 \\
\hline
\end{tabular}

\section{RESULTS AND DISCUSSION}

For the experimental group, the average clock times for performing the task before and after training were 31.2 and $30.6 \mathrm{sec}$, respectively. For the control group, these corresponding times were 31.4 and $30.7 \mathrm{sec}$. These times were not significantly different between the two groups. Each subject was given two estimation accuracy (AC) scores, one before and one after training. These scores were obtained by dividing the logarithm of the verbal estimates by their corresponding logarithm of the actual clock times. The means and standard deviations of the AC scores are presented in Table 1.

An analysis of variance performed on the AC scores with repeated measures within each group revealed a significant interaction between group type and experimental phase $[F(1,48)=4.07, p<.05]$. Furthermore, subjects in the experimental group were divided into two groups: the 8 most extreme overestimators $(\mathrm{AC}>1.0)$ and the 8 most extreme underestimators $(\mathrm{AC}<1.0)$ in the second experimental phase. These data are presented in Figure 1. A second analysis of variance with repeated measures within each group indicated a significant interaction between group and experimental session $[F(1,14)$

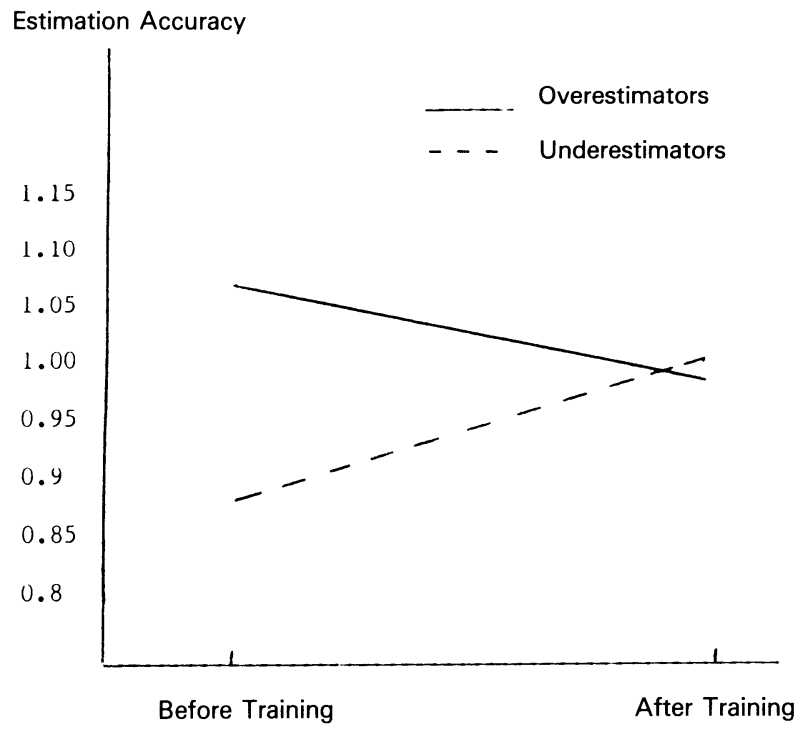

Figure 1. Estimation accuracy scores before and after training for overestimators and underestimators.
$=5.20, p<.05]$. These results clearly show that the level of accuracy of the control group remained virtually unchanged between the second and third sessions, whereas the training for the experimental group produced substantial improvement in accuracy.

This improved accuracy could not be explained by the greater focusing of attention on time as the result of the training, because this training did not produce longer estimated durations, but rather a differential effect for different subjects, resulting in overall greater accuracy. Moreover, the results could not be explained by increased familiarity with the psychomotoric task, possibly allowing for more attention allocation to the passage of time, since task familiarity had an equal effect for the experimental and control groups. Thus, the present results suggest that raising the awareness of time estimators to the problem of time sharing and optimal attentional division between task performance and the passage of time increases time estimation accuracy. Further research is needed in order to define and validate an optimal training method for calibrating time estimation.

\section{REFERENCES}

BURNSIDE, W. (1971). Judgment of short time intervals while performing mathematical tasks. Perception \& Psychophysics, 9, 404-406.

CAHOON, D., \& EDMonds, E. M. (1980). The watched pot still won't boil: Expectancy as a variable in estimating the passage of time. Bulletin of the Psychonomic Society, 16, 115-116.

Fraisse, P. (1984). Perception and estimation of time. Annual Review of Psychology, 35, 1-36.

FranKENhAUSER, M. (1959). Estimation of time. Stockholm: Almquist \& Wiksell.

GoPHER, D., \& BRICKNER, N. (1980). On the training of time sharing skills: An attentional viewpoint. In G. Carvick, M. Hazeltine, \& R. Durst (Eds.), Proceedings 24th Annual Meeting of the Human Factors Society. Santa Monica, CA: Human Factors Society.

HICKs, E. R. (1976). Effect of information feedback upon intentional consistency of time judgment. Acta Psychologica, 40, 265-270.

Hicks, E. R., \& MilleR, G. W. (1976). Transfer of time judgments as a function of feedback. American Journal of Psychology, 89, 303-310.

Hicks, E. R., Miller, G. W., Gaes, G., \& Bierman, K. (1977). Concurrent processing demands and the experience of time in passing. American Journal of Psychology, 90, 431-446.

LORDAHL, D. S., \& BERKowITZ, S. (1975). The watched pot does boil: A case of the wrong control group. Bulletin of the Psychonomic Society, $5,45-46$.

Priestly, J. B. (1968). Man and time. New York: Dell.

VROON, P. A. (1970). Effects of presented and processed information on duration experience. Acta Psychologica, 34, 115-121.

WICKENS, C. D. (1984). Engineering psychology and human performance. Columbus, $\mathrm{OH}$ : Charles E. Merrill.

ZAKAY, D., \& FAllaCH, E. (1984). Immediate and remote time estimation: A comparison. Acta Psychologica, 57, 69-81.

ZaKaY, D., NitZan, D., \& Glicksohn, J. (1983). The influence of task difficulty and external tempo on subjective time estimation. Perception \& Psychophysics, 34, 451-456.

(Manuscript received August 22, 1988.) 